\title{
Effect of Fig Tree (Ficus Sycomorus) Root Exudates on Root-Knot Nematode (Meloidogyne Javanica)
}

\author{
${ }^{1}$ Jada, M.Y., ${ }^{2}$ Oaya, C. S. And ${ }^{1}$ Stephen, S. N. \\ ${ }^{1}$ Department of Crop Protection, Moddibo Adama University of Technology, P. M. B. 2076, Yola, Adamawa \\ State - Nigeria. \\ ${ }^{2}$ Department of Agricultural Technology, Adamawa State College Agriculture, P. M. B. 2088, Ganye, Adamawa \\ State-Nigeria.
}

\begin{abstract}
The effect of fig tree (Ficus sycomorus) root exudates on root-knot nematode (Meloidogyne javanica) was evaluated in the Laboratory of the Department of Crop Production and Horticulture/Crop Protection, Modibbo Adama University of Technology, Yola in 2008. This was to determine the egg hatch and juvenile mortality of M. javanica and also the nematicidal properties of the root exudates. The experimental design used was the Completely Randomized Design (CRD) consisting of six (6) treatments replicated four (4) times for both $F$. sycomorus root exudates for egg hatch and juvenile mortality. The result obtained shows that, egg hatch in $10 \%$ concentration of $F$. sycomorus root exudates at 168hours of exposure was significantly higher (318.00) followed by $8 \%$ concentration (296.00) at 168hours and the least was observed in $2 \%$ concentration of $F$. sycomorus root exudates at 24 hours of exposure (97.00). Similarly, juvenile mortality at $100 \%$ concentration of F. sycomorus root exudates at 168hours of exposure was significantly higher (132.00) followed by 80\% concentration (107.00) at 168hours and the least was reported in $0 \%$ concentration at 24hours exposure (9.00) at $p \leq 0.05$ using the least significant difference (LSD) test for variables. The result clearly shows that, egg hatch and juvenile mortality in all the treatments increased significantly with increase in time of exposure and concentration of the root exudates. $70 \%$ of juvenile mortality was recorded on the $7^{\text {th }}$ day (168hours) at the highest concentration of $100 \%$, which further stressed that, F. sycomorus root exudates has nematicidal properties. The chemical analysis of the root exudates also reveals that, saponins, phenols, 3.5\% alkaloids and pH of 6.81 were confirmed.
\end{abstract}

Keywords: Concentration, Exudates, Eggs, Juveniles, Nematodes, Hatching, Mortality.

\section{Introduction}

Root-knot nematode (Meloidogyne spp.) is one of the most important plant parasitic nematode worldwide, causing a yield loss of 5\% out of the $14 \%$ estimated to be caused by all plant parasitic nematodes (Jackson et al., 2003). It is known to cause yellowing of leaves, fruit fall, flower abortion, stunted growth and in some cases complete yield loss (Adesiyan et al., 1990; Olabiyi et al., 1992; Jackson et al., 2003). Worldwide, Meloidogyne spp attack a wide range of plants from vegetables (Bridge, 1972), cereals (Jada, 2001), root and tuber crops (Idowu, 1985; Jada, 2007) and tree crops (Idowu et al., 1990). Different control measures have been used to control Meloidogyne spp. which includes chemical control measure that is successful but costly to economically low income farmers and less friendly to the environment. Other control measures include biological, physical, cultural techniques, use of plant extracts and the use of root exudates (Baker et al., 1994). Extracts from many plants purported to have anthelminthic effects are effective against soil nematodes. Effective plants includes both annuals and perennials, range from grasses and herbs to woody trees (Prot and Kornprobst, 1983; Jada, 2001). Ferris et al. (1992) suggested that, identification of chemical stimuli released by plant roots to be used as nematicides is needed. Ficus sycomorus root exudates is used as medicine against woophing cough by the local people in Nigeria. This work is therefore aimed at identifying the effect of $F$. sycomorus root exudates on $\mathrm{M}$. javanica egg hatch and juvenile mortality.

\section{Materials And Methods}

\section{Collection of Root Exudates}

A small pit $30 \mathrm{~cm}$ deep and $15 \mathrm{~cm}$ wide was dug to reach the roots. After the roots were found, a considerable portion of the root was selected and cut using an axe. To the remaining part of the root that was attached to the tree, a strong polythene bag was tied to avoid any external material from tempering with the root exudates. The cutting was done at about $5 \mathrm{pm}$ and the polythene was left over night and the sample was collected around $7 \mathrm{am}$ the following morning. The root exudates obtained was designated as $100 \%$ concentrate. 


\section{Maintenance of $M$. javanica culture}

Root-knot nematodes infested roots containing egg masses were collected from the Teaching and Research Farm of the Department of Crop Production and Horticulture, Modibbo Adama University of Technology, Yola. The egg masses were then inoculated into three (3) pots with tomato growing in them in the screen house.

\section{Preparation of Root Exudates}

The root exudates collected was designated as $100 \%$ concentrate. The root exudates was prepared in concentrations by taking $2 \mathrm{ml}$ of the $100 \%$ concentration of the root exudates mixed with $98 \mathrm{ml}$ of water to give $2 \%$ concentration, $4 \mathrm{ml}$ of the $100 \%$ concentration of the root exudates mixed with $96 \mathrm{ml}$ of water to give $4 \%$ concentration, $6 \mathrm{ml}$ of the $100 \%$ concentration of the root exudates mixed with $94 \mathrm{ml}$ of water to give $6 \%$ concentration, $8 \mathrm{ml}$ of the $100 \%$ concentration of the root exudates mixed with $92 \mathrm{ml}$ of water to give $8 \%$ concentration and $10 \mathrm{ml}$ of the $100 \%$ concentration of the root exudates mixed with $90 \mathrm{ml}$ of water to give $10 \%$ concentration.

\section{Inoculation of $M$. javanica eggs into $F$. sycomorus Root Exudates}

Infected tomato was uprooted from the culture prepared and egg masses of M. javanica were removed from the roots using forceps and needle according to Holbrook et al. (1983). The egg masses were then introduced into $1 \%$ sodium hyper chloride to release the eggs. The eggs were washed using water and 500 eggs were counted into each dilution of the root exudates including the control $(0 \%, 2 \%, 4 \%, 6 \%, 8 \%$ and $10 \%)$. Each of these were replicated four (4) times laid in a Completely Randomized Design (CRD) placed on a bench in the Laboratory of the Department of Crop Production and Horticulture/Crop Protection Modibbo Adama University of Technology, Yola in 2007.

\section{Effect of F. sycomorus Root Exudates on M. javanica Juvenile Mortality}

Two hundred (200) juveniles were counted and inoculated into the $100 \%$ concentration of the prepared root exudates. This was done when $20 \mathrm{ml}$ of the $100 \%$ concentration was taken and mixed with $80 \mathrm{ml}$ of water to give $20 \%$ concentration, $40 \mathrm{ml}$ of the $100 \%$ concentration mixed with $60 \%$ of water to give $40 \%$ concentration, $60 \mathrm{ml}$ of the $100 \%$ concentration mixed with $40 \mathrm{ml}$ of water to give $60 \%$ concentration, $80 \mathrm{ml}$ of the $100 \%$ concentration mixed with $20 \mathrm{ml}$ of water to give $80 \%, 100 \%$ concentration was taken as the last treatment.

\section{Chemical Analysis}

Preliminary chemical analysis of the root exudates was carried out in the Laboratory to determine the alkaloids and other constituents responsible for the nematicidal action. $2 \mathrm{ml}$ of the root exudates was taken in a test tube, shaken and frothing that persisted on heating confirmed the presence of saponin. In another test, $1 \mathrm{ml}$ of the sample was taken and three (3) drops of $1 \%$ iron chloride $\left(\mathrm{Fecl}_{3}\right)$ solution added indicated a colour change to green for a short time which gradually fades away and is typical of phenols. Furthermore, $1 \mathrm{ml}$ of the sample was taken and mixed with $3 \mathrm{ml}$ of picric acid, green precipitate was formed, which indicated the presence of alkaloids. The percentage alkaloids were calculated thus:

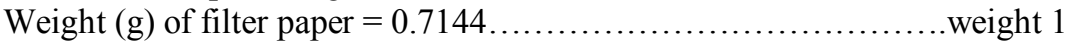

Weight $(\mathrm{g})$ of filter paper and weight of sample $=0.7494 \ldots \ldots \ldots \ldots$ weight 2

Weight $(\mathrm{g})$ of sample $=25 \mathrm{~g}$

$\%$ alkaloids $=\underline{\mathrm{W}}_{2}-\underline{\mathrm{W}}_{1} \quad \mathrm{X} \underline{100}$

$\mathrm{W}_{2} \quad 1$

$=\underline{0.7494-0.7144} \times \underline{100}$

25

$=3.5 \%$

Furthermore, the $\mathrm{pH}$ of the sample was determined using $\mathrm{pH}$ model of $\mathrm{Ph} 5-25 \mathrm{pH}$ meter, giving a $\mathrm{pH}$ of 6.81 .

\section{Data Collected}

The number of hatched M. javanica juveniles were observed under the stereomicroscope and counted for each treatment on exposure for 24, 48, 72 and 168hours (7day) respectively. Similarly, the numbers of dead M. javanica juveniles were counted at 24, 48, 72 and 168hours (7days) respectively. Needle tip was used to move each juvenile three (3) times under a stereomicroscope. Those juveniles that did not respond in the form of movement were assumed dead. 


\section{Statistical Analysis}

Data collected were subjected to analysis of variance appropriate to Completely Randomized Design (CRD) according to Gomez and Gomez (1984). While the means that were significant were separated using the Least Significant Difference (LSD) as described by Fisher and Hedge (1937).

\section{Results}

Hatched at 24 and 48hours of exposure was recorded in $10 \%$ concentration of the F. sycomorus root exudates (245.00 and 284.00), 8\% concentration (173.00 and 213.00), 6\% (158.00 and 177.00), $0 \%$ (145.00 and 219.00 ) and the least was obtained in $2 \%$ concentration of the fig tree root exudates (97.00 and 108.000). The highest number of eggs hatched at 72 and 168hours of exposure was seen in $10 \%$ concentration of the fig tree root exudates (300.00 and 318) significantly followed by $8 \%$ (249.00 and 296.00), $0 \%$ (248.00 and 302.00), $6 \%$ (193.00 and 262.00), 4\% (162.00 and 185.00) and least was observed in 2\% concentration of the fig tree root exudates (121.00 and 142.00) at $\mathrm{P} \leq 0.05$ using the least significant difference (LSD) test for variables. There was significant difference among the treatments as shown in Table 1.

Table 1: Effect of $\boldsymbol{F}$. sycomorus root exudates on cumulative egg hatch of $M$. javanica for

$24,48,72$ and 168 hours.

\begin{tabular}{lllll}
\hline $\begin{array}{l}\text { Hours of exposure } \\
\text { Concentration (\%) }\end{array}$ & 24hours & 48hours & 72hours & 168hours \\
\hline \hline & & & & \\
$0 \%$ & 145.00 & 219.00 & 248.00 & 302.00 \\
$2 \%$ & 97.00 & 108.00 & 121.00 & 142.00 \\
$4 \%$ & 125.00 & 142.00 & 162.00 & 185.00 \\
$6 \%$ & 158.00 & 177.00 & 193.00 & 262.00 \\
$8 \%$ & 173.00 & 213.00 & 249.00 & 296.00 \\
$10 \%$ & 245.00 & 284.00 & 300.00 & 318.00 \\
S. E. & 9.93 & 13.48 & 15.50 & 12.07 \\
LSD & $72.61 * *$ & $98.51^{*}$ & $113.29^{*}$ & $88.18^{* *}$ \\
\hline
\end{tabular}

Note:**=highly significant $(\mathrm{P} \leq 0.01),{ }^{*}=$ significant $(\mathrm{P} \leq 0.05), \mathrm{LSD}=$ least significant difference, $\mathrm{S} . \mathrm{E} .=$ standard error.

The highest cumulative mortality of M. javanica juveniles exposed at 24 and 48hours was recorded in $100 \%$ concentration of the Ficus sycomorus root exudates (65.00 and 84.00) followed by $80 \%$ (53.00 and 69.000), 60\% (42.00 and 53.00), 40\% (31.00 and 45.00) and the least was observed in $0 \%$ concentration of the fig tree root exudates $(9.00$ and 15.00) respectively. Similarly, $100 \%$ concentration of F. sycomorus root exudates gave the highest cumulative mortality of M. javanica juveniles exposed at 72 and 168hours $(99.00$ and 132.00 ) followed by $80 \%$ (84.00 and 107.00), 60\% (72.00 and 91.00), 40\% (64.00 and 75.00), 20\% (49.00 and 61.00 ) and the least was reported in $0 \%$ concentration of the fig tree root exudates as shown in Table 2.

Table 2: Effect of $\boldsymbol{F}$. sycomorus Root Eudates on cumulative Mortality of $M$. javanica Juveniles on Exposure for 24, 48, 72 and 168hours.

\begin{tabular}{lcccc}
\hline & \multicolumn{4}{c}{ Hours of Exposure } \\
Concentration (\%) & 24 hours & 48 hours & 72 hours & 168 hours \\
\hline $0 \%$ & 9.00 & 15.00 & 30.00 & 42.00 \\
$20 \%$ & 21.00 & 36.00 & 49.00 & 61.00 \\
$40 \%$ & 31.00 & 45.00 & 64.00 & 75.00 \\
$60 \%$ & 42.00 & 53.00 & 72.00 & 91.00 \\
$80 \%$ & 53.00 & 69.00 & 84.00 & 107.00 \\
$100 \%$ & 65.00 & 84.00 & 99.00 & 132.00 \\
S.E. & 0.63 & 1.10 & 1.19 & 0.96 \\
LSD & $4.59 * *$ & $8.04 * *$ & $8.70 * *$ & $7.02 * *$ \\
\hline
\end{tabular}

Note: **=significant $(\mathrm{P} \leq 0.01) *=$ significant $(\mathrm{P} \leq 0.05), \mathrm{LSD}=$ least significant difference, S.E. $=$ standard error. 
Saponin was confirmed when $2 \mathrm{ml}$ of the root exudates was taken in a test tube and shaken. $1 \mathrm{ml}$ of the root exudates was taken and 3 drops of $1 \%$ iron chloride $\left(\mathrm{Fecl}_{3}\right)$ solution added which indicates the presence of phenol. Furthermore, $1 \mathrm{ml}$ of the root exudates was taken and mixed with $3 \mathrm{ml}$ of petric acid, green precipitation was formed which indicated the presence of alkaloids of $35 \%$. The $\mathrm{pH}$ of 6.81 was also determined.

Table 3: Chemical Analysis of Ficus sycomorus Root Exudates

\begin{tabular}{ll}
\hline Treatments & Nematicidal Action \\
\hline $2 \mathrm{ml}$ exudates + olive oil emulsion & \\
$1 \mathrm{ml}$ exudates +3 drops of $1 \% \mathrm{Fecl}_{3}$ & Saponin \\
$1 \mathrm{ml}$ of exudates mixed with $3 \mathrm{ml}$ petric acid & Phenols \\
PH5-25pH meter & Alkaloids $-3.5 \%$ \\
& $\mathrm{pH}=681$
\end{tabular}

\section{Discussion}

This work shows that, more eggs of Meloidogyne javanica hatched at the highest concentration of the root exudates (10\%) and with increase in the time of exposure (7days). This means that, the root exudates could not suppress or inhibit egg hatching instead stimulated them. This might be due to the fact that, the egg shell was weakened or even dissolved by the root exudates of Ficus sycomorus, thereby releasing more juveniles. This work is consistent with the findings by Riga et al. (2000) who reported that, root exudates increased egg hatching in nematodes by $46.6 \%$. This invariably means that, at lower concentration of the root exudates (2\%), egg hatching was low at all the time of exposure. However, the low concentration did not totally inhibit egg hatching, but rather delayed it. This study also agrees with Magnarelli and Nowierski (2004) who suggested that, the root exudates were antagonistic to cyst and root-knot nematodes as a result of the toxic metabolites in the root exudates.

The effect of fig tree (F. sycomorus) root exudates on cumulative mortality of $M$. javanica juveniles at different time of exposure $(24,48,72$ and 168hours) shows that, dead count was observed at all the concentration levels of the root exudates for all the time of exposure including the control. Hence, dead count increases with increase in concentration levels of the root exudates and time of exposure. This study agrees with Noling (2005), who stated that, there is a corresponding increase in juvenile mortality of M. javanica with increase in concentration of root exudates and also with the time of exposure. Baker et al. (1994) also validated this finding when they reported that, $100 \%$ mortality of $\mathrm{M}$. javanica juveniles were recorded after 7 days (168hours) of exposure and at higher level of root exudates concentration (100\%).

Chemical analysis to determine the nematicidal constituent of the F. sycomorus root exudates shows that, 3.5 alkaloids, phenols, saponins and $\mathrm{pH}$ of 6.81 were confirmed. The presence of the above mentioned indicated that, F. sycomorus root exudates has nematicidal properties and also had considerable on cumulative the results obtained. This work further stressed the findings by Peterson and Clinch (1994), who suggested that, several potentially stimulating and toxic substances have been isolated from F.sycomorus root exudates. These includes; spectine, autofine, phenols, saponins, alkaloids, tylophonine etc.

\section{Conclusion}

The study has shown that, egg hatch and juvenile mortality in $M$. javanica increased with increase in time of exposure to $F$. sycomorus root exudates. The highest egg hatch and juvenile mortality was recorded on the $7^{\text {th }}$ day (168hours) at $10 \%$ concentration for egg hatch and $100 \%$ concentration of the root exudates for juvenile mortality respectively. Hence, the highest egg hatch recorded was 317 at $10 \%$ concentration level and at the longest time of exposure while the highest juvenile mortality was 132 at $100 \%$ concentration level of the root exudates and at longest period of exposure. It was also discovered that, F. sycomorus had no inhibitory effect on $M$. javanica eggs but had nematicidal properties that killed the juveniles. Furthermore, the chemical analysis of the root exudates reveals that, it had the following constituents, alkaloids (3.5\%), phenols, saponins and a $\mathrm{pH}$ of 6.81. F. sycomorus is abundantly found in forests and savannah regions of Nigeria, the root exudates can easily be tabbed and elucidated for synthetic manufacture of the identified chemicals for uses as nematicides. 


\section{References}

[1]. Adesiyan, S. O.,Adeniti, M.O., Caveness, F. E. and Fawole, B. (1990). Nematode pest of Tropical crops. Hgeria) Plc, Ibadan, pp.1929.

[2]. Baker, K. R., Hussey, R. S. and Krusberg, L. R. (1994). Plant and Oil Nematodes: Societal impact focus for the future 26: $127-137$.

[3]. Bridge, J. (1972). Plant Parasitic Nematode on Irrigated Crops in Northerrn States of Nigeria. Samaru Miscellaneous paper 42, $111 \mathrm{pp}$.

[4]. Ferris, H., Castro, C. E. and Caswell- Chen, E. P. (1992). Beyond Pesticides-Biological Approaches to Management in Califonia

[5]. For Management of Plant Parasitic Nematodes. No. 117, 2pp.

[6]. Jackson, G.V.H., Ruabete, Y.K. and Wright, J.G. (2003). Burrowing and lesion nematodes of bananas $2^{\text {nd }}$ edition . Secretariat of the Pacific Community Pest Advisory Leaflet, No. 5.

[7]. Jada, M. Y. (2001). Effect of Water Soluble Extracts of Three Mimosaceae Plants on Penetration Ability of Meloidogyne incognita Juveniles into Roots of Tomato C. V. Roma VF. Nigerian Journal of Tropical Agriculture. Vol. 3:10-14.

[8]. Jada, M. Y. (2007). Short Communication Responses of Some Hausa Potato [Salanostemon rotcardifollices (Pair) J. K. Morton] Cultivars to the Root-knot Nematode Meloidogyne javanica (Treub) Chitwood in Nigeria. International Journal of Agriculture and Biology. http://www.fspublishing. 1560- 8530/2007/09-4.

[9]. Noling, J. W. (2005). Nematode Management in Tomatoes, Pepper and Egg plants. Cooperative Extension Service, Institute of Food and Agricultural Sciences, University of Florida. P. 1-4.

[10]. Olabiye, T. I., Babatola, J.O. and Ogyegunurade, E. A. (1992). In vitro assessement of some extracts for nematicidal properties. In eds. Fawole, B. J.O.A., Egunjobi, S.O., Adesiyan, O. A. and Idowu, A. A. The Biology and Control of Nematode Pests of Crops in Africa. Proceedings of the First Regional Symposium on the Biology and Control of Nematode Pests of Food Crops in Africa. University of Ibadan 26-29 $9^{\text {th }}$ July, 1992.

[11]. Peterson, R. T. and clinch, N. J. L. (1994). Use of Trees by Livestock 7: Ficus chatham, UK Natural Resources Ins

[12]. Riga, E., Welacky., Potter, J., Anderson, T., Topp, E. and Tenuta, A. (2000). The impact of Plant Residues on Soya bean cyst Nematode Heterodera glycines. The Canadian Journal of Plant Pathology 23 (2): 168-173. 